\title{
Thirteen ways of looking at institutional history: a model for interconnected digital exhibitions from science archives
}

\author{
Venkat Srinivasan ${ }^{1}$, T.B. Dinesh ${ }^{2}$, Bhanu Prakash$^{2} \&$ A. Shalini ${ }^{\bullet}$
}

\begin{abstract}
Over the past decade, there have been many efforts to streamline the accessibility of archival material on the web. This includes easy display of oral history interviews and archival records, and making their content more amenable to searches. Science archives wrestle with new challenges, of not just putting out the data, but of building spaces where historians, journalists, the scientific community and the general public can see stories emerging from the linking of seemingly disparate records. We offer a design architecture for an online public history exhibit that takes material from existing archives. Such a digital exhibit allows us to explore the middle space between raw archival data and a finished piece of work (like a book or documentary). The National Centre for Biological Sciences (NCBS) digital exhibit is built around thirteen ways to reflect upon and assemble the history of the institution, which is based in Bangalore, India. (A nod to Wallace Stevens' poem, "Thirteen Ways of Looking at a Blackbird"). The exhibit tries to bring to light multiple interpretations of NCBS, weaved by the voices of over 70 story tellers. The material for the exhibit is curated from records collected to build the Centre's archive. The oral history excerpts, along with over 600 photographs, official records, letters, and the occasional lab note, give a glimpse into the Centre's multifaceted history and show connections with the present.
\end{abstract}

\section{Keywords}

Institutional history; Digital exhibition; Science archive; History of biology; India

\footnotetext{
${ }^{1}$ Archivist, National Centre for Biological Sciences, Tata Institute of Fundamental Research, India; ${ }^{2}$ Servelots Infotech Pvt Ltd, Bangalore, India. $₫$ venkats@ncbs.res.in.
} 
Over the past decade, there have been many efforts to streamline the accessibility of archival material on the web. This includes easy display of oral history interviews and archival records, and making their content more amenable to searches. In 2009, the NUMERIC project of the European Commission surveyed the state of digitization across European institutions. Based on responses from 98 archives, it revealed that less than ten percent of the full holdings of archives are typically available in a digital format. ${ }^{1}$ The surveyed archives also felt $41.6 \%$ of their material need not be digitized due to being "insufficiently relevant for open access to a wide clientele" 2 . However, given the volumes of archival material, even small percentages can add to be millions of digital documents, as would be the case for large national collections.

Archives wrestle with new challenges, of not just putting out the data, but of building spaces where historians, journalists, the scientific community and the general public can see stories emerging from the linking of seemingly disparate records.

At the National Centre for Biological Sciences (NCBS), we were faced with the problem of putting together a digital exhibition of its history from newly sourced archival material. One particular obstacle with presenting institutional histories is the quest for depth, breadth and meaning while still engaging the reader with a narrative. To explain our process, we think it necessary to start with a story.

It was the end of the roaring 1920s, and the L. Bamberger and Co. store had done pretty well. It sold everything from clothing to footwear to furniture from their headquarters in Newark, New Jersey. And in 1929, after forty years of operation, Louis Bamberger and his sister, Caroline Bamberger Fuld, sold their business to R.H. Macy and Company of New York. ${ }^{3}$ It was good timing. Just weeks later, Wall Street crashed in October 1929. Businesses collapsed and people were out of jobs. The events in late 1929 would prove to be a catalyst for the Great Depression that set in through the 1930s.

Meanwhile, Bamberger and his sister had made money and wanted to funnel their fortunes into something else. They harboured the idea of setting up a medical school, and through friends, reached out to a man who had gained some reputation as a "reformer of higher education"4. In 1910, he had written a report on medical education. Over the next century, this report would continuously shape the structure of medical education in North America, and then, the world. It set standards for the teaching curriculum and training of students, and triggered the shutting down of many schools. There is no way to overstate its influence. The report was an inflection point that established one standardized model of education across the US to this day. The report had a rather lengthy title: "Medical Education in the US and Canada: A Report to the Carnegie Foundation for the Advancement

\footnotetext{
${ }^{1}$ Roswitha Poll, "NUMERIC: Statistics for the Digitisation of European Cultural Heritage," Program: Electronic Library and Information Systems 44, No. 5 (2010): 122-131. doi: https://doi.org/10.1108/00330331011039481

${ }^{2}$ Ibid.

${ }^{3}$ Linda G. Arntzenius, Institute for Advanced Study: An Introduction (Princeton [NJ]: Institute for Advanced Study, 2005), 8

4 The Institute for Advanced Study: Annual Report $1979 / 80$ (Princeton [NJ]: Princeton University Press, 1980$), 15$
} 
of Teaching." ${ }^{5}$ But it came to be known as the Flexner Report, in honour of the author, Abraham Flexner (1866-1959).

Flexner was not trained in medicine. He had been a lecturer in Greek and Latin and in general, was a thinker on education. In those first few decades in the $20^{\text {th }}$ century, he became a professional assessor of sorts. In 1908, he wrote a book summarizing the deficiencies of higher education in the US. ${ }^{6}$ Then the Flexner Report was published in 1910. In 1914, John Rockefeller asked him to write about regulating prostitution in Europe. ${ }^{7}$

By the time the Bamberger siblings had reached out to him in the early 1930s regarding the building of a medical school, Flexner was one of the most prominent people in medical education. ${ }^{8}$ But in the 1920s, he had also started thinking more broadly about basic research and higher education. Soon after the end of the First World War, in 1921, he had written a speech titled "The Usefulness of Useless Knowledge." This was later published in Harper's Magazine in 1939. ${ }^{9}$ Flexner's mind was on the odd juxtaposition of learning and destruction that existed in the times of the War. In this article, he opens with the following question:

"Is it not a curious fact that in a world steeped in irrational hatreds which threaten civilization itself, men and women-old and young-detach themselves wholly or partly from the angry current of daily life to devote themselves to the cultivation of beauty, to the extension of knowledge, to the cure of disease, to the amelioration of suffering, just as though fanatics were not simultaneously engaged in spreading pain, ugliness, and suffering?"10

To Flexner, there was great use in this so-called useless knowledge. So, in 1929, when he was approached by the two gentlemen who were friends of the Bamberger siblings, he had a different idea:

“(...) At our interview I informed them that my competency was limited to the education field and that in this field it seemed to me that the time was ripe for the creation in America of an institute in the field of general scholarship and science, resembling the Rockefeller Institute in the field of medicine-developed by my brother Simon - not a graduate school, training men in the known and to some extent in methods of research, but an institute where everyone-Faculty and Members - took for granted what was known and published, and in their individual ways endeavored to advance the frontiers of knowledge."11

\footnotetext{
${ }^{5}$ Abraham Flexner, "Medical Education in the United States and Canada. From the Carnegie Foundation for the Advancement of Teaching, Bulletin Number Four, 1910," Bulletin of the World Health Organization 80, no. 7 (2002): 594-602.

${ }^{6}$ Abraham Flexner, The American College: A Criticism (New York: Century Company, 1908).

${ }^{7}$ Abraham Flexner, Prostitution in Europe, Introduction by John D. Rockefeller, Jr. (New York: Century Company, 1914).

${ }^{8}$ Arntzenius, 9.

9 Abraham Flexner, “The Usefulness of Useless Knowledge,” Harper's Magazine 179, no. 10 (1939): 544-52.

${ }^{10}$ Ibid., 544.

11 Arntzenius, 8.
} 
The Bamberger siblings were taken by Flexner's vision and abandoned their plans for a medical school. Instead, they decided to invest USD 5 million in a graduate centre for learning, what would soon be called the Institute for Advanced Study, situated on the Princeton University campus. ${ }^{12}$

The 1930s was also a period of intense persecution in Europe, with thousands of people fleeing from the influences of Nazism and fascist governments. This period included hundreds of scholars who moved to North America in search of a place to continue their intellectual inquiries. Many, including Albert Einstein (1879-1955) and John von Neumann (1903-1957), landed at the Institute.

There have been various attempts to emulate the model of the Institute for Advanced Study. A behavioural sciences institute set up at Stanford University in 1954 was one of the first such attempts. A consortium named Some Institutes for Advanced Study (SIAS) emerged in the early 1990s. ${ }^{13}$ Today, it includes the original IAS, the Center for Advanced Study in the Behavioral Sciences in Stanford, the National Humanities Center in North Carolina, and the Swedish Collegium for Advanced Study in Uppsala, Sweden, among others.

But there have been informal attempts as well to follow the founding principles of the IAS. In a memo to the Bamberger siblings, Flexner said the institute would be designed so that it

“(...) should be small, that its staff and students or scholars should be few, that administration should be inconspicuous, inexpensive, subordinate, that members of the teaching staff, while freed from the waste of time involved in administrative work, should freely participate in decisions involving the character, quality, and direction of its activities, that living conditions should represent a marked improvement over contemporary academic conditions in America, that its subjects should be fundamental in character, and that it should develop gradually." 14

However, a cursory search of this statement on the Internet does not lead to the IAS. These are most prominently seen as the founding principles adopted by the National Centre for Biological Sciences (NCBS) in Bangalore, India. ${ }^{15}$

\footnotetext{
12 Ibid., 12.

13 "Some Institutes for Advanced Study," Swedish Collegium for Advanced Study, accessed 31 March 2018, http://www.swedishcollegium.se/subfolders/International_Links/SIAS.html

14 Arntzenius, 11

15 “History of NCBS, March 1997," National Centre for Biological Sciences, accessed 31 March 2018, https://www.ncbs.res.in/history.
} 


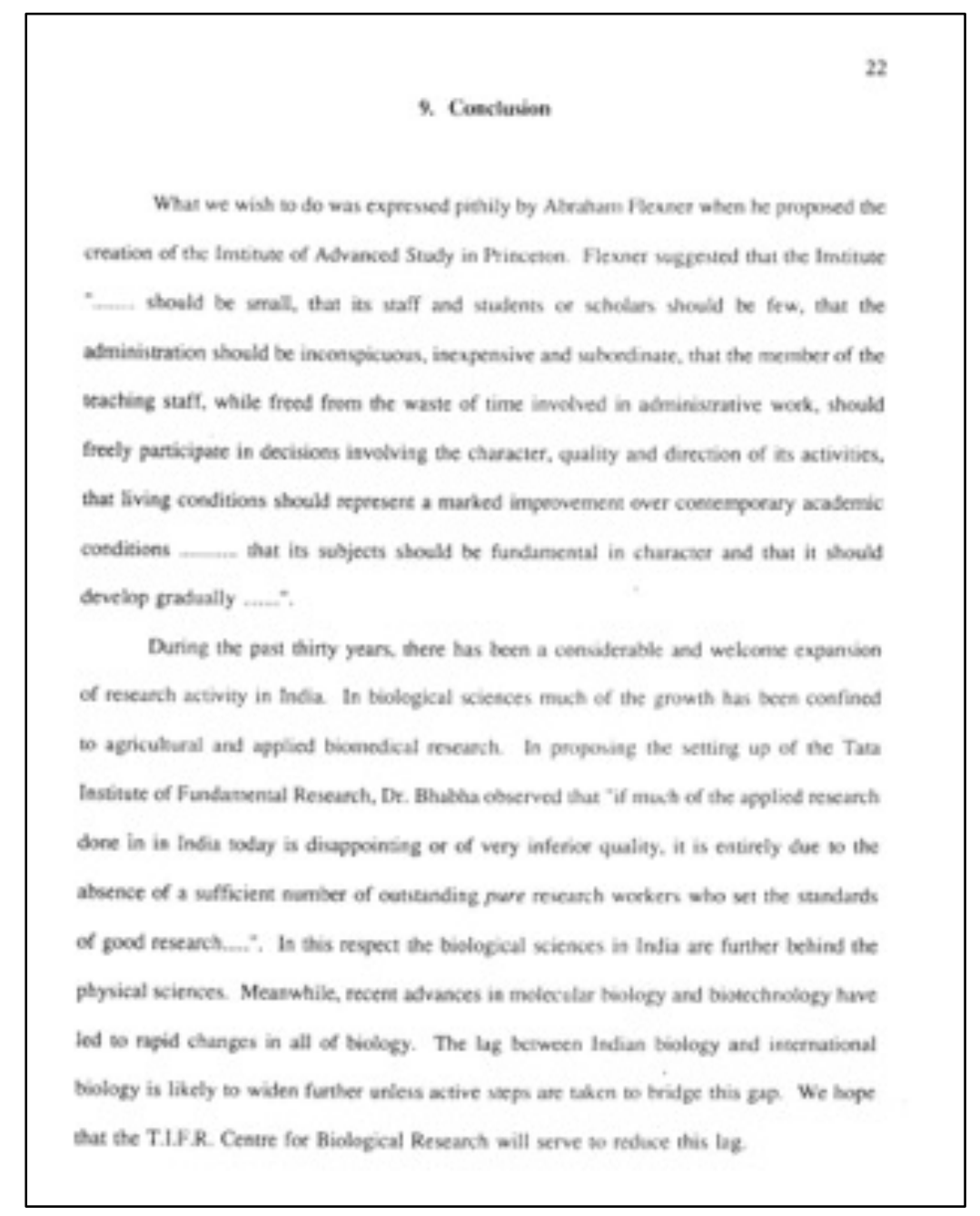

Figure 1. Typescript extract of the 1990 Proposal document for a Centre for Fundamental Research in Biological Sciences, Tata Institute of Fundamental Research. (Archives, National Centre for Biological Sciences)

"What we wish to do was expressed pithily by Abraham Flexner when he proposed the creation of the Institute of (sic) Advanced Study in Princeton," wrote Obaid Siddiqi, one of the co-founders of NCBS, in the 1990 proposal document for NCBS. Siddiqi went on to quote Flexner's founding principle almost verbatim as seen in Figure 1. In fact, they pointedly redacted just one portion of that principle in their proposal, as seen in the last sentence: “(...) that living conditions should represent a marked improvement over contemporary academic conditions (....) that its subjects should be fundamental in character, and that it should develop gradually."16 By replacing Flexner's focus on America with ellipses and retaining everything else, the co-founders of the Institute were also signalling a global relevance of the principles to the primary evaluators of the proposal document, scientists, administrators and politicians in the Indian government.

We are not trying to establish a causal relation by starting with a story about a mall in Newark in the 1920s and ending with an extract from a 1991 proposal document of a

\footnotetext{
16 Typescript of Proposal for a Centre for Fundamental Research in Biological Sciences (Tata Institute of Fundamental Research, 1990), 22, Uncatalogued, Archives, National Centre for Biological Sciences.
} 
biology institution in Bangalore. This narration was to simply illustrate a contextual understanding of decisions taken at different points in time.

This contextual underpinning is especially necessary in institutional history narratives where one has to step out of the examined object both spatially and temporally to make sense of it. As the protagonist, Grace Marks, says in Margaret Atwood's 1996 book, Alias Grace, "When you are in the middle of a story, it isn't a story at all, but only a confusion, a dark roaring, a blindness (...) It is only afterwards that it becomes anything like a story when you're telling it to yourself or someone else."17

Narrating institutional histories is very much about trying to understand the layers and context. As we mentioned earlier in this paper, the quest is to find a way to bridge depth, breadth and meaning. Instead of having a fixed narrative with a linear path, we decided to exploit the advantages of the digital platform.

The National Centre for Biological Sciences (NCBS) digital exhibition is built around thirteen ways to reflect upon and assemble the history of the institution, which is based in Bangalore, India. The title, 13 Ways (Figure 2), pays homage to Wallace Stevens' poem, Thirteen Ways of Looking at a Blackbird. ${ }^{18}$ The exhibition tries to bring to light multiple interpretations of NCBS, weaved by the voices of over 70 story tellers. ${ }^{19}$ The material for the exhibition is curated from records collected to build the Centre's archive as well as others at the TIFR Archives and from publicly accessible records. The oral history excerpts, along with over 600 photographs, official records, letters, and the occasional lab note, give a glimpse into the Centre's multifaceted history and show connections with the present.

The institutional history of NCBS is presented like a traveler's exploration into a new land, with the findings spread across the (digital) pages. The exhibition is thought of as a cross between a filofax and a traveler's notebook, where one can insert and remove chapters, photographs, oral history interviews and field notes. We expect this to be a continuous process, ensuring that the story does not get fixed in one point of view or in one moment in history.

\footnotetext{
${ }_{17}$ Margaret Atwood, Alias Grace (New York: Anchor, 1997), 298.

18 Wallace Stevens, The Collected Poems of Wallace Stevens (New York: Vintage, 1990), 92

19 "13 Ways," Archives, National Centre for Biological Sciences, accessed 31 March 2018, http://archives.ncbs.res.in/exhibit/13ways/.
} 


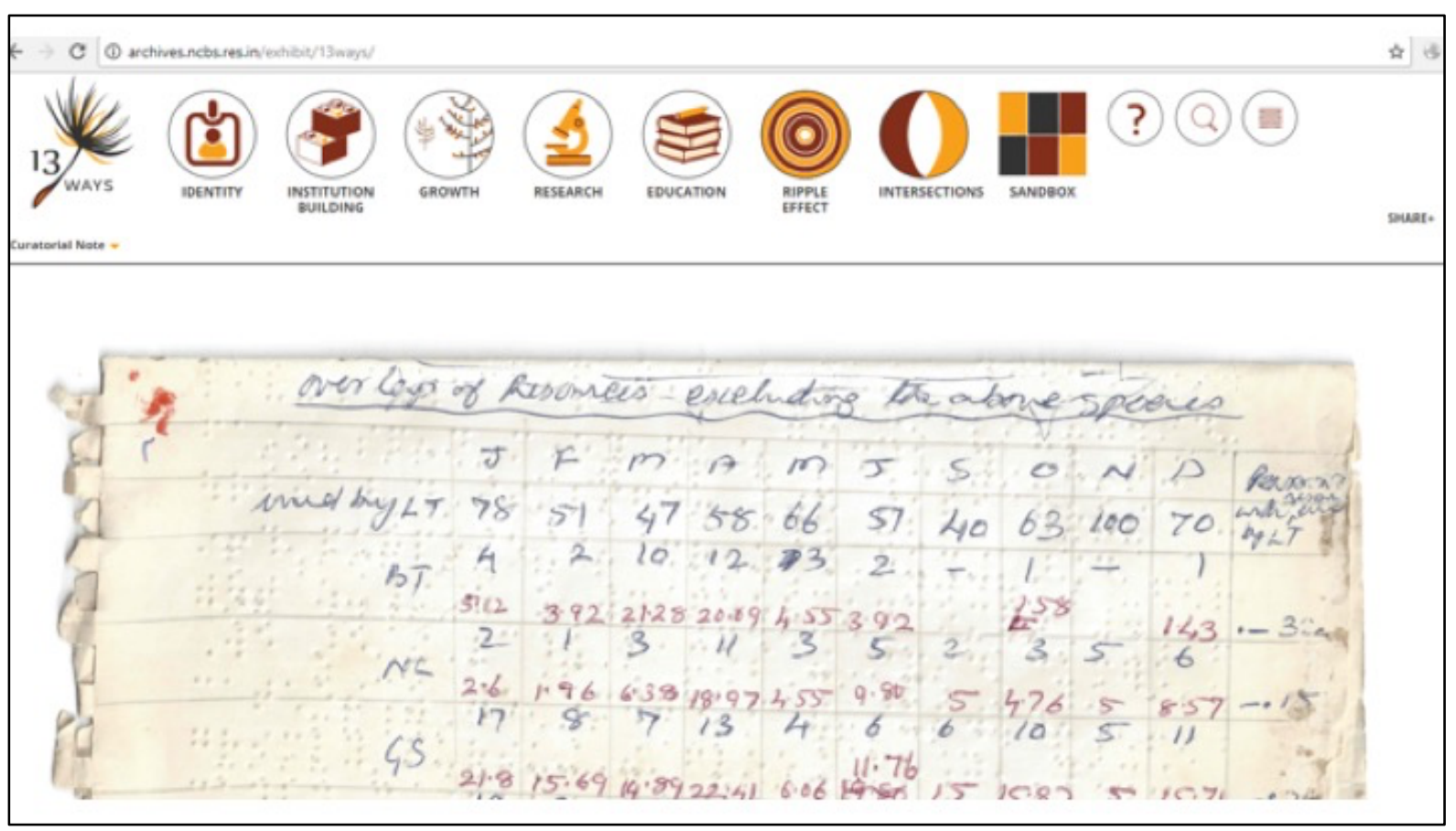

Figure 2. 13 Ways website cover image (with different images upon every click) for the 13 Ways exhibition. ${ }^{20}$

Our initial ideas for the exhibition lay emphasis on a single narrative, hinging on character development and plots. But one of the difficulties with institutional histories is the primacy of the institution itself as the protagonist. In her influential 1985 book, How Institutions Think, Mary Douglas discusses the way in which institutions tend to herd their members around a coherent narrative: "Institutions systematically direct individual memory, and channel our perceptions into forms compatible with the relations they authorize. They fix processes that are essentially dynamic, they hide their influence, and they rouse our emotions to a standardized pitch on standardized issues." ${ }^{21}$

As institutions grow, they become bolder in their steps toward the future. And they may become more timid in their understanding of their past. Institutions sometimes rely on a defined narrative of their past that can shepherd them into a prosperous future, one where a perception of self-assurance, harmony and resolve might be dominant.

In such an ecosystem, we felt it important to consciously steer clear of a single narrative. The exhibition is non-linear and is built on a basic idea that there are many ways of sizing up the history of a research institute. It has seven themes: shaping an identity for research in the biological sciences, on institution building, on the idea of growth over the years, on research trajectories, on role of education, on the effects of setting up a new biology center - on individuals, on research, and on other places. And finally, a theme on

\footnotetext{
${ }^{20}$ http://archives.ncbs.res.in/exhibit/13ways/

${ }^{21}$ Mary Douglas, How Institutions Think (Syracuse [NY]: Syracuse University Press, 1986), 91.
} 
issues that are part of discourse in society - gender, hierarchy, outreach - and NCBS happens to be a microcosm for these issues. ${ }^{22}$

In each of the themes, we have picked out archival material - interviews, documents, photographs, lab notes - that speak to its ideas. We mesh oral histories with photographs, with current journal articles, with marginalia in old manuscripts. These are expanded upon through 24 chapters within the themes. The written part in each chapter within a theme stands as the narrative that guides the visitor through the material, and filling gaps where necessary.

Besides the seven narrative themes, the 13 Ways exhibition has six data visualization widgets to sample the archival material in a different way. The aim is not to build more data visualization widgets. ${ }^{23}$ It is simply to see how existing visualization tools can be used in the world of archives and be used to thread narratives with them. The widgets are based on existing open source software widgets built for other purposes. We extract their value in storytelling, and also in bringing them together to develop various ways of looking at one topic. For instance, Timeline, based on tools developed by Knight Labs, is a chronological story told based on the timestamps of various archival records. ${ }^{24}$ Peopleplex is another widget that shows up as a nodal network of people and stories, based on tools developed by Christopher Manning. ${ }^{25}$ SpaceTour is a Google street view-like spatial tour with embedded stories through oral history interviews and archival documents using Pannellum (Figures 3, $4,5) \cdot{ }^{26}$

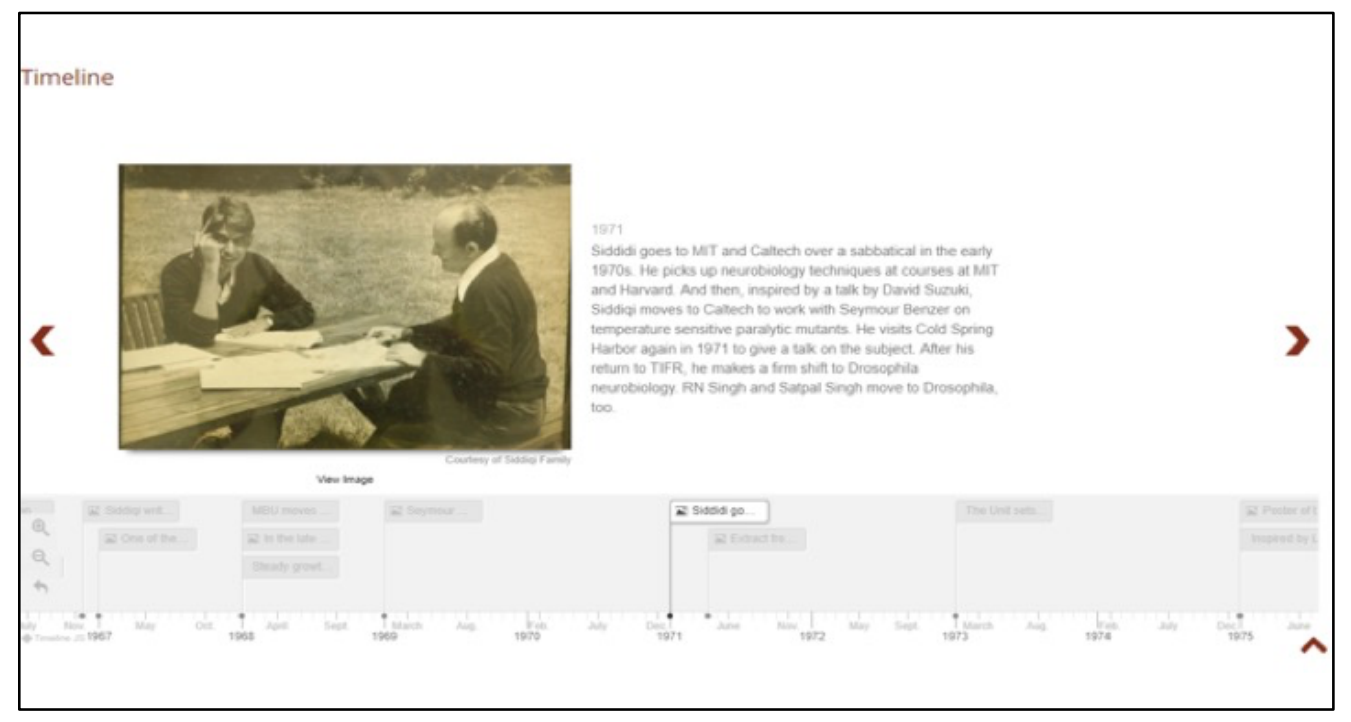

Figure 3. Screenshot of the Timeline in the 13 Ways exhibition - Sandbox Theme. ${ }^{27}$

\footnotetext{
${ }^{22}$ Archives, National Centre for Biological Sciences, "13 Ways."

${ }^{23}$ Ibid.

24 "Timeline JS," Knight Lab, accessed 31 March 2018, https://timeline.knightlab.com.

25 "Building Hamiltonian Graphs from LCF Notation," Christopher Manning, accessed 31 March 2018, http://christophermanning.org.

26 "A Lightweight Panorama Viewer for the Web," Pannellum, accessed 31 March 2018, https://pannellum.org/.

27 http://archives.ncbs.res.in/exhibit/13ways/\#/theme/sandbox/introduction/
} 


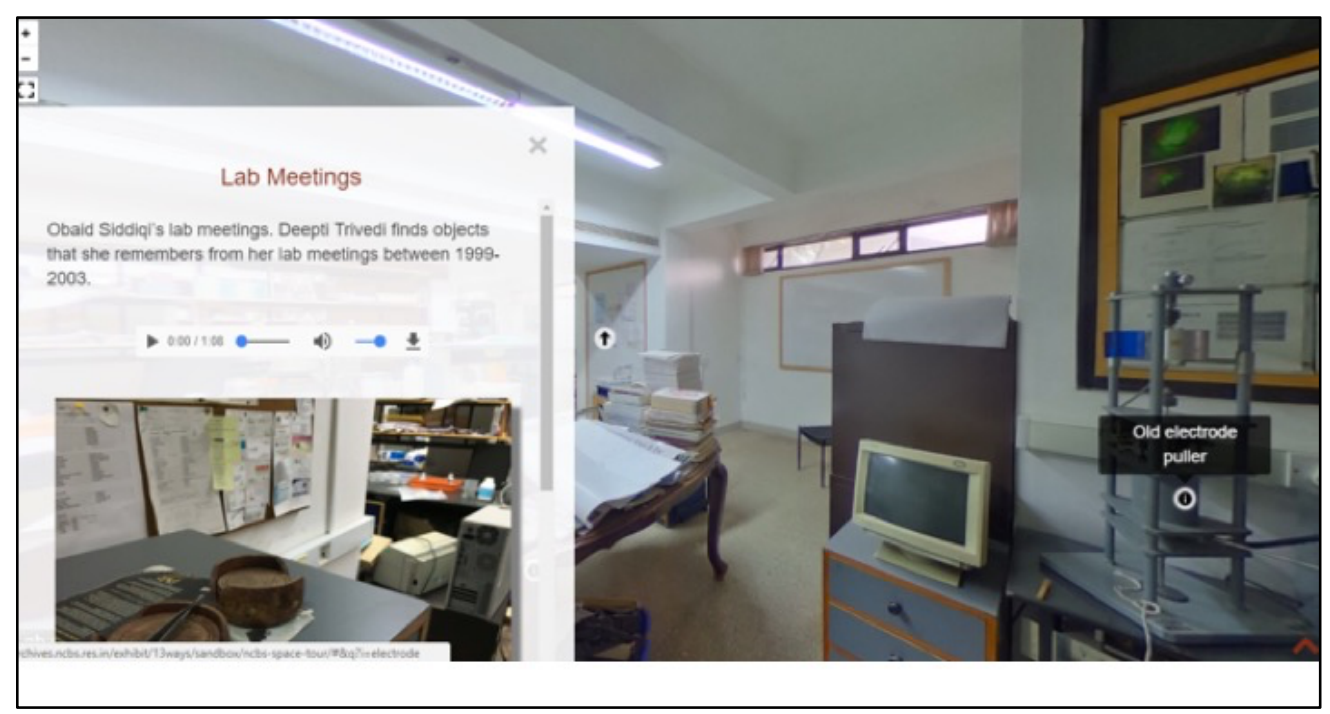

Figure 4. Screenshot of the SpaceTour widget in the 13 Ways exhibition - Sandbox Theme. ${ }^{28}$

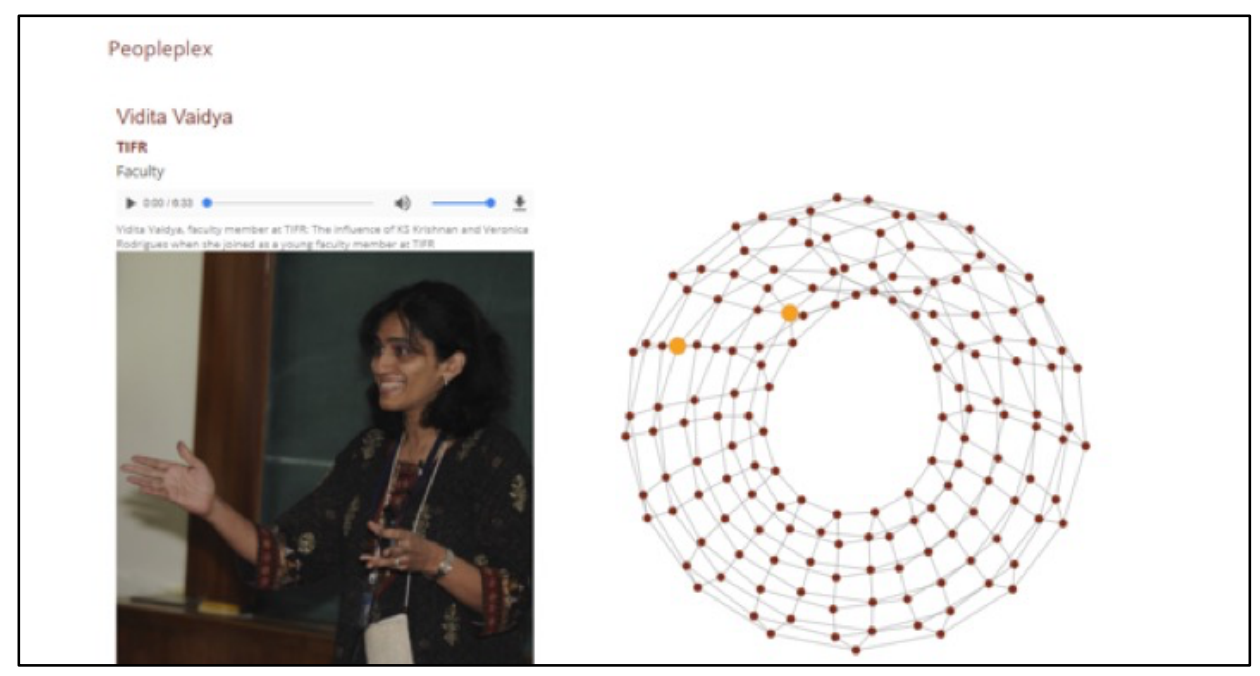

Figure 5. Screenshot of the Peopleplex widget in the 13 Ways exhibition - Sandbox Theme. ${ }^{29}$

We concede that the exhibition, even with its various chapters, is still the point of view of a single storyteller. But we developed this structure for the exhibition to give us and future storytellers the freedom to take any archival object and embed it easily within the exhibition, based on how they interpret it. For instance, let us consider the NCBS proposal document with Flexner's comment on the founding principles of IAS. There are a couple of ways of interpreting this benign extract. One is, of course, to see it as an attempt to build an

${ }^{28}$ Ibid. 
independent space for biology in India, and a place where scientists would have the freedom to explore their lines of inquiry. The archival proposal document is part of a narrative on 'Space and Autonomy' within the Identity theme of the exhibition. ${ }^{30}$ Another interpretation is evident upon digging a little deeper into the quoted excerpt, "(...) that administration should be inconspicuous, inexpensive, subordinate, that members of the teaching staff, while freed from the waste of time involved in administrative work (...)" This hints at an emphasis on the hierarchy within a scientific institution, between scientists and their support staff. The archival proposal document is featured again in a different narrative on the interactions between communities within NCBS, in the Intersections theme. ${ }^{31}$

This freedom to interpret also allows us to see other documents in new ways. For instance, in a 1990 letter to the Dean of the Physics Faculty at TIFR, Veronica Rodrigues, a biologist at the Institute, critiques the system that used to address female faculty by their marital status: Shrimati or Smt, to denote the prefix for married women in India, and Kumari for unmarried women (Figure 6). "I feel that appending (Kum), (Smt) or (Ms) to the names of women scientists in official correspondence is not only unnecessary, but also unacceptable," she writes, "This practice should be stopped unless you consider qualifying men scientists with (Shri) or (Kumar)." The typewritten letter has a handwritten response from the administration on it: "Do we write Smt or Ms Dr Veronica Rodrigues. In her case, as she desires we may not use the words Mrs/Ms (...) There are no specific orders/guidance from Dean PF (Physics Faculty)." The response illustrates an inability to understand the problem and a certain preference for unwritten procedure rather than common sense. ${ }^{32}$

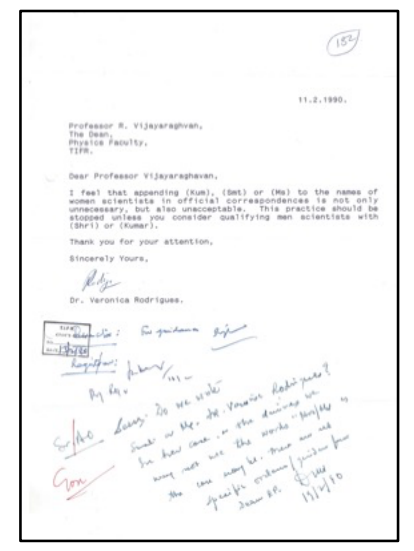

Figure 6: Correspondence from Veronica Rodrigues to R. Vijayaraghavan. February 11, 1990.33

\footnotetext{
30 "13 Ways: Institution Building: Space and Autonomy," Archives, National Centre for Biological Sciences, accessed 31 March 2018, http://archives.ncbs.res.in/exhibit/13ways/\#/theme/institution-building/space-and-autonomy. 31 "13 Ways: Intersections: NCBS Community," Archives, National Centre for Biological Sciences, accessed 31 March 2018, http://archives.ncbs.res.in/exhibit/13ways/\#/theme/intersections/ncbs-community.

${ }^{32}$ Correspondence from Veronica Rodrigues to R. Vijayaraghavan, 11 February 1990, Uncatalogued, Archives, National Centre for Biological Sciences, Bangalore, India.

33 Archives National Centre for Biological Sciences, Bangalore, India.
} 
Within the exhibition, this letter is featured in a chapter on gender biases in science. The same letter could easily be sampled and interpreted in other ways like the attitude of bureaucracy, and of course, as part of the biography of Rodrigues, who served as a mentor for many generations of scientists in the TIFR-NCBS complex.

There is also freedom in displaying individual small stories from oral history interviews and making them part of a broader theme. Through interviews, people shared a variety of stories that are not documented anywhere else. The exhibition's filofax structure allows us to place the excerpts within themes and string together pliable narratives to contextualize these memories. ${ }^{34}$ Here are a few samples. Soon after his arrival at NCBS, Sumantra Chattarji, a neuroscientist, talks about being stressed about his lack of productivity on the new campus and starting to study chronic stress in the amygdala portion of the brain. H. Mohan, a technology scientist, talks about cannibalism in the animal house. Mitradas Panicker, a retired scientist, explains how he figured out why the pregnant animals he was supposed to get from Hyderabad were not pregnant when they landed in Bangalore. Govind Swarup, former director of the National Centre for Radio Astrophysics, talks about his favorite question in student interviews involving a laddoo, an Indian dessert. U.B. Poornima, an architect and one of the early staff members at NCBS, tells us about how chatris - rooftop structures that allow people to stand under shade in an open environment were constructed on top of the NCBS old building but never got used except for keeping air conditioners cool. T. Eswar, a cook, explains how the campus cafeterias handle scale and the quality control checks for each food item before it is served to a community member. Sanjay Sane, a former student and current faculty, describes the moment when he stared out the window and saw a swarm of butterflies, as the time when he started thinking about locally rooted research and working with organisms that were a departure from the model organism structure.

A structure like this exhibition with non-rigid boundaries addresses another inherent problem in narrating history. These narrations often need beginnings, middles, an end, and an arc to pull the reader along. And so, there is a hunt for those dramatic turn of events. These events sometimes surface by assigning significance on whatever one can find. Take the attempts to pinpoint the founding date for NCBS. The Department of Atomic Energy issued a sanction order on 22 October 1991, to build NCBS by sending a note to NCBS' parent institute, the Tata Institute of Fundamental Research (TIFR). ${ }^{35}$ But they issued another letter on 23 October 1991. The second letter was identical in content and corrected for a typo in the cost breakdown in the first letter. ${ }^{36}$ The Records Office at TIFR has the original document for the 22 October letter, but only a copy of the 23 October letter has been found so far. How do you apply definitive dates to the 'founding' of an institution? Does one take 22 or 23 October with the typo corrected? Or does one consider the date (8 February 1991) of the lease deed between TIFR and the University of Agricultural Sciences, on whose land

\footnotetext{
34 Archives, National Centre for Biological Sciences, "13 Ways."

${ }^{35}$ Correspondence from R. Narayanan, Department of Atomic Energy, Government of India to Registrar, Tata Institute of Fundamental Research, 22 October 1991, Uncatalogued, Records Room, Tata Institute of Fundamental Research, Mumbai, India.

${ }^{36}$ Copy of correspondence from R. Narayanan, Department of Atomic Energy, Government of India to Registrar, Tata Institute of Fundamental Research, 23 October 1991, Uncatalogued, Archives, National Centre for Biological Sciences, Bangalore, India.
} 
NCBS sits today? ${ }^{37}$ Or is 2 March 1991 the launch date, since that is when Bangalore authorities told TIFR that no permission was needed from them for the deal to go through? ${ }^{38}$

There are two ways of approaching this question of timing. The Timeline widget lays archival documents across using their timestamps as the narrative anchor. But a digital exhibition structure might offer a big-tent approach to history, without anchoring to a set narrative. For instance, when asked about the origins of NCBS, various people kept independently talking about a National Biological Laboratory through the 1960s and 1970s as a precursor to the NCBS. ${ }^{39}$ There is no known link between the two efforts, but it illustrates a broader attempt in the country to develop a home for biology. Vague memories from retired scientists are placed near 'factual' documents. One might get the sense that by October 1991, there were two sentiments: people who had already resigned to the slowness of the process, and people feeling a center was already in place. These are detailed in two narrative chapters - in the "Science in India" chapter in the Identity theme ${ }^{40}$ and in the "Paper Trail" chapter in the Institution Building theme. ${ }^{41}$ Building such a structure for a digital exhibition allows us to explore the ambiguous interpretive space that emerges between raw archival data and a historical narrative.

In the next phase, in late 2018, we will have the physical and digital archive open to the public, with a detailed catalogue. In addition, we hope to release an open source storytelling portal in an 'Exhibitions' section on the Archives that enables the public to draft newer narratives and connections between the different kinds of archival material, thus allowing multiple ways of seeing to coexist.

Following that, in the third phase, we hope to start forming parallel networks of catalogues and stories linked to each other across institutions, places, events, people and time. This will be an effort to build an interconnected digital archival of science with pilot material from five science archives in India and then, later, from other parts of the world. This will be made available through a digital platform to historians, journalists, scientific researchers and the general public.

\footnotetext{
${ }^{37}$ Copy of Lease Deed between Tata Institute of Fundamental Research and the University of Agricultural Sciences, 8 February 1991, Uncatalogued, Archives, National Centre for Biological Sciences, Bangalore, India.

${ }^{38}$ Copy of correspondence from Office of the Assistant Commissioner, Bangalore Sub-Division to Administrative Officer II, Tata Institute of Fundamental Research, 2 March 1991, Uncatalogued, Archives, National Centre for Biological Sciences, Bangalore, India.

39 "13 Ways: Identity: Space for Biology," Archives, National Centre for Biological Sciences, accessed 31 March 2018, http://archives.ncbs.res.in/exhibit/13ways/\#/theme/identity/space-for-biology.

40 "13 Ways: Identity: Science in India," Archives, National Centre for Biological Sciences, accessed 31 March 2018, http://archives.ncbs.res.in/exhibit/13ways/\#/theme/identity/science-in-india.

41 "13 Ways: Institution Building: Paper Trails," Archives, National Centre for Biological Sciences, accessed 31 March 2018, http://archives.ncbs.res.in/exhibit/13ways/\#/theme/institution-building/paper-trails.
} 


\section{Acknowledgments and disclosure}

This paper is an edited version of previous presentations of the project and the reader is likely to find portions of this text in presentation recordings on the Internet. Funding for this project is from the National Centre for Biological Sciences, Tata Institute of Fundamental Research (TIFR). We acknowledge the support of the TIFR Archives and over a hundred members of the faculty, students, staff, and affiliate historians, designers, developers and editors at NCBS and TIFR. Detailed acknowledgments are in the About section of the digital exhibition (http://archives.ncbs.res.in/exhibit/13ways/\#/about). We thank Indira Chowdhury and Aparna Uppaluri for their insights that shaped the narratives in the digital exhibition. The corresponding author reports no conflict of interest. The co-authors work at Servelots, a not-for-profit software development agency interested in working on annotations of and narratives with digital objects. 